\title{
Foresight of the Global Digital Trends
}

\author{
Konstantin B. Kostin \\ Saint-Petersburg State University of Economics, St. Petersburg, Russia
}

\begin{abstract}
The purpose of this article is to examine the contemporary developments of the global digital trends and investigate the most perspective digital technologies crucial for international companies. The relevance of foresight methodology application is justified. The paper's focus is on future trends of digital technologies by providing a brief literature review in the fields of digital technologies and relevant marketing resources. Key assumptions, expectations and uncertainties about the future are re-evaluated. It is justified that long-term thinking is crucial to frame future strategies not only for governments and citizens but also for both small and international companies. Three global trends within the field of digital technologies are investigated: artificial intelligence, block chain and big data. The marketing resources which are currently arising and developing with the highest potential of dominating and revolutionizing the future of marketing are described: internet of things, social media, virtual and augmented reality. The author used the example of augmented reality expansion and development as one of the most promising global trends. Survey methodology was applied to evaluate the potential of augmented reality (AR) application using one of the most promising international industry adopters: the tourism industry. The AR mobile apps generated \$ 2 billion in revenue as of the end of 2016 and according to the investigations the AR market could grow to $\$ 120$ billion by 2020 . The research results have shown that $84 \%$ to $100 \%$ of generation $Y \& Z$ consumers, whose consumption patterns would shape future demand, see clear benefits in using augmented reality applications in tourism industry.
\end{abstract}

\section{Keywords}

Global digital trends, international business, foresight, augmented reality, international tourism.

\section{Introduction}

Digitalization nowadays is unquestionably one of the most dynamic areas in the business world. The breakthrough developments in recent decades in digital technologies are astounding. In fact, to keep up with the recent developments in digital technologies sounds to be easier than it actually is. As the range of possibilities for marketers to interact with the environment is increasing and changing, it is a real challenge for them to find the optimal way to conduct their marketing activities. On the one hand to stay up to date about new developments is crucial enough, but to follow the right predictions regarding the future on the other hand is even much more important. Investing today in digital technologies and activities of tomorrow would ultimately lead to business success if the forecasts were accurate.

This paper is an attempt to evaluate and analyze the global trends in digital technologies and relevant marketing resources and focuses on the most promising marketing resource for the tourism industry: augmented reality.

The paper has the following structure. The theoretical background section provides an outline of what to expect from the terms "foresight" and "global trends"; moreover, their relevance from today's marketing and business point of view is discussed. In the following section the two global marketing trends are investigated: digital technologies and marketing resources. The most promising marketing resource, the augmented reality, is analysed and its current and future potential for the tourism industry is calculated. A critical evaluation of the findings and relevant conclusions complete the analysis.

\section{Theoretical background}

The objective of this section is to lay the theoretical foundation for further and deeper analysis of the selected world trends in the following section. To meet this goal, it is expedient to review the 
meaning and importance of the terminology of foresight and global trends.

\subsection{Definition and relevance of foresight}

"Foresight is a purposeful process of developing knowledge about the future of a given unit of analysis or a system of actors, which is aimed at action in the form of public or private policy making, strategizing and planning, and that foresight is frequently a participatory, involved and collaborative process". This broad definition of foresight can be broken down into two parts. It could be concluded that "foresight is:

1) an organized social process; an intervention (in an organization),

2) to create actionable and domain/context specific information or knowledge about the future" (European Commission, 2014).

Furthermore, the theory on foresight contains three different perspectives, or levels. The first level is the epistemology of foresight. Under this approach the foresight is seen as an activity creating knowledge. It represents the foundations for claims to scientific knowledge through foresight and answers the question "How can we gain knowledge about the future (or futures)? (Piirainen \& Gonzalez, 2015, p. 5). The second level deals with the different foresight methods. This means to conceptualize "foresight as an organizational or social intervention and developing a theory of why foresight has the impact we observe or expect". This leads to the following questions: "How do we organize foresight effectively? What impacts can we expect from foresight and why?" (Piirainen \& Gonzalez, 2015, p. 5). The third level embraces foresight as development and application of domain-specific theories that explains and predicts the behaviour of the sociotechnical system of interest and gives grounds to conjectures about the future. This perspective should answer the following question: "what is likely to happen in the future and why?" (Piirainen \& Gonzalez, 2015, p. 5).

Especially for international companies, foresight plays a crucial role for their sustainability and ultimately success. The international companies have to constantly adapt to the changing markets which are influenced by different factors. These factors, to name a few, could be political and economic trends, socio-cultural trends of needs and lifestyle of consumers, trends of emerging technologies and technological discontinuities or competitors' actions and trends related to the products or services availability. In order to stay competitive, companies have to anticipate future challenges to be prepared and to be able to act as well as possible (Khripunova, Vishnevskiy, Karasev, \& Meissner, 2014, p. 149).

\subsection{Foresight methodology}

There are different methods that could be used to forecast future trends. One of the most established methods is called "horizon scanning". The steps of horizon scanning method in a schematic form are presented in picture 1 .

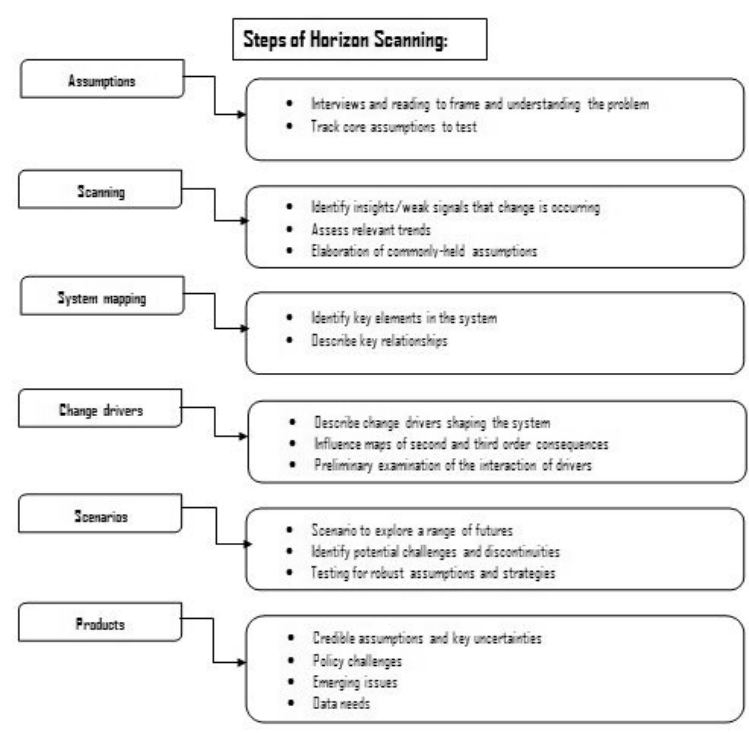

Picture 1 Steps of horizon scanning Source: European Commission, 2015, p. 14.

A number of international corporations use it as part of their risk management strategy, for emerging issues analysis, and to identify wild cards (events with low probability, potentially high-impact risks). The European Commission defines it as "the systematic outlook to detect early signs of potentially important developments. These can be weak (or early) signals, trends, wild cards or other developments, persistent problems, risks and threats, including matters at the margins of current thinking that challenge past assumptions. Horizon Scanning can be completely explorative and open or be a limited search for information in a specific field based on the objectives of the respective projects or tasks. It seeks to determine what is constant, what may change, and what is constantly changing in the time horizon under analysis. A set of criteria is used in the searching and/ or filtering process. The time horizon can be short-, medium- or long-term.” There- 
fore, horizon scanning represents a valuable tool for assessing and anticipating future developments. The provisions for horizon scanning can be desk research, automated and semi-automated literature search, bibliometrics, patent searches, text mining, science maps, conference scanning, environmental scanning, expert opinions, scenarios, storytelling, matrices, platforms, social media scans and much more.

\subsection{Definition and relevance of global trends}

As was already mentioned, the world is in constant motion and there is nothing more constant than change. In a faster and more complex way than ever before, capital and labour are globally dispersed. Technological innovations especially have a significant impact on the economy as well as on the way human beings manage their lives. Furthermore, the acceleration of this constant change increases year to year (EY, 2015, p. 1).

To have a closer look on the relevance of this issue, first of all it is important to clarify what a global trend exactly is. The Cambridge dictionary defines a global trend as "a general development or change in a situation that affects many countries of the world" (Cambridge Dictionary , 2017). These large, transformative, global forces have a far-reaching impact on business, economies, industries, societies and individuals (EY, 2015, p. $1)$.

Dealing more precisely with the subject, it can be observed that on the one hand, the topic is very complex. The reason for this is that there could be found a huge amount of different global trends affecting the world ranging from demography, gender, urbanisation, resources and environment to health, transport, information and education and a lot of others just to name a few examples. Moreover, these global trends can again be further subdivided according to different regional groups like America, Europe, Middle East, Asia, Polar Regions and even space (Ministry of Defence UK, 2014, p. 6).

On the other hand, it is shown that the topic of global trends has high relevance and is current. Not only do government related institutions like for example the National Intelligence Council (US), the Ministry of Defence UK or the United Nations publish very detailed and in-depth reports regularly, but also management consultancies like for example the Boston Consulting Group, A.T. Kearney and EY underline the challenges which result from future global trends within their analyses and reports.

Overall it could be concluded that long-term thinking is crucial to frame future strategies not only for governments and citizens but also for both small domestic and large international companies. Therefore, it is necessary to re-examine key assumptions, expectations and uncertainties about the future. Furthermore, the longer time frame is essential because issues like terrorism, cyber-attacks, biotechnology and climate change invoke high stakes and will require sustained collaboration to address (National Intelligence Council, 2017, p. 6).

Of course, it is not possible to have the definite answer to the questions arising from future trends and challenges. However, it is of fundamental importance to think critically about the implications embedded in these global trends today, as well as looking for new developments (EY, 2015, p. 1).

\section{Analysis of selected global trends}

Based on the relevance of the topic and the theoretical background investigation, this part deals with the analysis of specific global trends. Therefore, the primary focus is on the trends within the selected fields of digital technologies and marketing resources.

\subsection{Digital technologies}

During the last few decades, digital technologies have excelled dramatically. After the agricultural revolution and the industrial revolution the mankind is currently in the era of digital revolution. Not only do companies digitize the way they function but also their products and services are digitized which makes society become more autonomous, managed by digital technologies (Kapteina, 2017).

There is a tremendous amount of different digital trends, but only the most crucial with the highest impact on global economy and with greatest future potential were selected. These trends include artificial intelligence, block chain and big data which are analysed in greater detail below.

\subsubsection{Artificial Intelligence}

Artificial Intelligence comprises different technologies which makes it possible for IT systems to sense, comprehend and to act. This results in three capabilities, i.e. computers are able to: 
1) perceive the world and collect data,

2) analyse and understand the information collected, and

3) make informed decisions and provide guidance based on the analysis in an independent way.

Moreover, artificial intelligence provides for learning from experience and changing their processing and behaviour based on this learning (Batalier \& Harris, 2016, p. 6).

Artificial intelligence includes endless applications in a lot of different areas which can make processes much more effective and efficient. Two good examples are within the field of healthcare and banking. In healthcare, artificial intelligence technologies could be used in a lot of ways for the most widely varying tasks and activities in order to deliver a total solution. Routine and predictable tasks such as appointment scheduling can be automated, while activities such as e-consulting and biomedical research would use technology to supplement human actions (Batalier \& Harris, 2016, p. 12).

In banking, transactions are being pushed toward higher efficiency through automation, while higher effectiveness through artificial intelligence is the objective for activities like for example security and identity management. For services such as financial advising and retirement planning, human interaction is substantial. Nevertheless, such activities can be supported by expert systems, automating some tasks and augmenting others (Batalier \& Harris, 2016, p. 13).

\subsubsection{Blockchain}

Blockchain is a radical rethinking of how we pay for things but also the way how we verify who owns these things and who has the right to buy or sell them. "At a very high level, though, the blockchain is a decentralized ledger, or list of all transactions across a peer-to-peer network." The most famous example for a blockchain is the cryptocurrency "Bitcoin" (PwC, 2016, p. 1).

With the help of this technology, users are able to transfer value across the Internet without the need for a central third party. Both the buyer and the seller interact with each other directly without the need of verification by a trusted third party intermediary. A transaction record is created but information which could identify individuals is encrypted so no personal information is shared (PwC, 2016, p. 2).
This technology offers diverse opportunities but also challenges. On the one hand, blockchain technology could be used to secure and verify any type of transaction. This includes simple goodsfor-cash exchanges but also complex transaction management. It results from the fact that the ownership and origin of a transaction is recorded in the blockchain and verified at every following step so agreement among all parties involved in a transaction is guaranteed. On the other hand, the blockchain brings new challenges, especially for financial institutions as they are no longer needed as a trusted third-party middleman for transactions (PwC, 2016, p. 2).

\subsubsection{Big data}

"Big data" deals with the dynamic, large and disparate volume of data which has been created by different parties as people or tools and machines. With the help of new, innovative and scalable technology, it collects, hosts and analyses an enormous amount of data to derive business insights in the field of consumer, risk, profit, performance, productivity management and extended shareholder value. It is typically characterized by the volume, variety, velocity and veracity of utilized data (EY, 2014, p. 2).

Organizations need to understand which knowledge they need to be able to make strategic operational decisions creating added value for the company. To meet this objective, as a first step companies have to sort through all available data in order to identify trends and correlations driving positive change in business behaviour. In a second step, companies have to add external information and combine it with the organizational information in order to achieve in-depth insights which can contribute to the company's success (EY, 2014, p. 2).

Business environment is in a constant and rapid change. Especially nowadays, future predictions become more and more important to stay competitive. Data analysis using statistical predictive modelling techniques represents a valuable tool to support and improve organization's business strategy (EY, 2014, p. 2).

\subsection{Marketing resources}

Before giving an insight in the global trends regarding marketing resources it is necessary to explain this term, as there are many different views on resources of marketing. According to Davcik \& Sharma (2016, p. 5548) "Marketing resources represent broad value propositions that affect the 
stakeholders in any business and firms that generally deploy these resources to gain a competitive advantage in the market." As a result, marketing resources include any action which is initiated by a business, which affects its stakeholders in any way. These actions can either be physical or human processes or any other proposition or technique that has an effect on buying decisions or brand perception of stakeholders. Overall businesses try to create or maintain competitive advantages through the deployment of their marketing resources (Davcik \& Sharma, 2016, p. 5548).

The goal of the following section of this paper is to identify the marketing resources which are currently arising or developing and could dominate or revolutionize the future of marketing. Where necessary, the respective trend will first be described and then assessed from a marketing point of view.

\subsubsection{Internet of things}

One technology which has high potential to be a dominating marketing resource of the future is the Internet of Things (IoT). By integrating a variety of smart devices into a cooperative network which interacts with and adapts to physical surroundings the Internet of Things will offer a wide range of entirely new possibilities to marketers. Through the integration of virtual intelligence, businesses will not only be able to increase effectiveness, but also customer satisfaction can be increased through the possibility to learn and improve more effectively (Gong, 2016, p. 2).

According to Rogers Bacon, \& Chahal (2016, p. 16) the investments in these computer intelligence systems in 2017 are predicted to be three times as high as they have been in 2016. This is a quite ambitious figure which can be seen as a prediction of a future technology.

Marketers will be given the opportunity to completely revolutionize the way a brand communicates with its stakeholders. They will cut down on people's interactions with screens, instead of following an advertisement their stakeholders will be able to directly communicate with a physical machine which will learn from the interaction in order to improve steadily. Moreover, the machine has the potential to more precisely meet the demand of a wider range of people (Rogers et al., 2016, p. 16).

These artificial intelligence devices in combination with Internet of Things will, sooner or later, be able to get integrated in all kinds of physical items humans deal with. From learning about habits and uses of people businesses get a lot of information in order to improve their marketing and establish or even enlarge their competitive advantage. Any interaction of a person with a device working with Internet of Things and artificial intelligence provides the business with useful content to constantly increase customer satisfaction, which will further result in higher brand awareness and a positive brand perception (Gong, 2016, pp. 6-7).

\subsubsection{Social media}

Even if it is already highly developed as a marketing resource for companies, social media still has a huge potential to become even more important for marketing a business. As social networking platforms contain a tremendous amount of information on the users gained through the way they interact and what they are interested via analysing the clicks' and likes' patterns, businesses are given the opportunity to easily carry out market segmentation and reach the right target group. Moreover, companies can once again meet consumer demands in a more effective and clear-cut way. It has to do not only with what consumers request, but also with the needs of people which they themselves have not identified yet. Hence the marketing activities of a company would be tailored towards future buying decisions of those customers (Carlson \& Lee, 2015, pp. 85-86).

The effects from these activities which companies perform on social media will not only become more effective with market segmentation, but also would serve as a unique way to create long-term relationships with the target group. The most important thing for businesses is to know how social media operates and which possibilities it has to offer. In the next steps, marketing managers have to carefully analyse and decide on which operations to focus on in order to reach the highest level of effectiveness (Carlson \& Lee, 2015, pp. 85-86).

According to Courtney $(2015$, p. 2) social media platforms offer an excellent opportunity to get the support for the content published by a company. Which social media platform to use depends on which purpose a business wants to achieve with their marketing activities.

If social media platforms are properly utilized by a company, this may induce earned media content. This form of online marketing has a considerably high potential for companies as a marketing resource. Through reposts or sharing of owned content by stakeholders it is possible to win an 
incredible amount of people. According to Burcher (2012, p. 22) earned social media content is oftentimes a direct response of well-established and executed owned or paid content. Even if this kind of marketing resource is already being used by many big players around the globe, the prospects for this technique as a marketing tool to become even much more important is considerably high (Rogers et al., 2016, p. 17).

\subsubsection{Virtual Reality/Augmented Reality}

The recent years brought about another marketing resource which offers completely new opportunities for companies. A technique called virtual reality (VR) or further augmented reality (AR) is already available for companies, but still a very low number of firms take advantage of this technology. Moreover, experts say that the vast majority of people around the world are still not aware of what VR/AR is and how it works, which means that there is high potential for this technique as soon as large numbers of consumers understand how it works and how to operate with it (Jackson, 2015).

By creating a simulated environment with computers, virtual reality offers people the possibility to see a 3D virtual world experience. VR can attract many human senses such as touch, vision and hearing for example. It is even possible to integrate smells into the virtual reality. All this given information is adapted to the virtual world which can be seen through VR. Augmented reality works in the same way, though one of the most important differences is that AR integrates reallife components into the virtual world (Jackson, 2015).

According to Rogers et al. (2016, p. 18) there is a need to present something virtual to consumers, otherwise it is much more difficult to attract their awareness and attention. Integrating augmented reality into smartphones would offer a great opportunity for businesses to easily attract the target group with new and interesting information. With some all-new devices being launched in the near future these technologies will be available and affordable for the mass market, which is essential for these hi-tech applications in order to be used by businesses as a marketing item (Rogers et al., 2016, p. 18).

Virtual reality and augmented reality represent great opportunities to extend the amount of delivered information. Gee (2016) argues, that mixed reality will be even more important for some companies, as it allows a person to experience the real world and virtual world altogether through special mapping sensors. Mixed reality will offer consumers a completely new possibility of instore shopping. Especially car industry will highly benefit from that, as car dealers will be able to display virtually generated cars to their customers before even being launched (Gee, 2016).

\section{Critical evaluation}

After the selected global trends have been analysed in detail in the previous section, the following section provides a brief critical evaluation of these trends.

Regarding digital technologies: it must be considered, that this market is changing at a very rapid pace and is characterized by innovative technologies which have a significant impact on markets and society. It is crucial for companies to recognize digital trends as early as possible in order to use the opportunities these trends have to offer and furthermore stay competitive.

As far as marketing resources are concerned based on the literature review presented and the analysis conducted it is important to outline the importance of applying the foresight methodology to map the most promising marketing resources. As marketing resources represent a very complex and dynamic environment, these foresights might not always come true and it is quite challenging to make the right predictions. Furthermore, it must be carefully examined, whether the particular marketing resources will be applied in the described spectrum and how their application will vary between different industries. Finally, it should be considered, that due to digitalization other aspects like personal customer contact can potentially vanish away even though customers might attach importance to this.

Based on the foresight methodology applied the augmented reality marketing resource was selected to be the most promising for the future using the tourism industry as the example of AR application's adopter, with the relevant justification presented in the next section.

\section{Research findings and results}

As was already described, augmented reality is "an enhanced image or environment as viewed on a screen or other display, produced by overlaying computer-generated images, sounds, or other data on a real-world environment" (Dictionary.com, 2017). The integration of digital information with the user's environment in real time is termed as 
augmented reality. Unlike virtual reality, which creates a totally artificial environment, augmented reality uses the existing environment and overlays new information on top of it. The apps for Augmented Reality are written in special 3D programs that allow the developer to tie animation/contextual digital information in the computer program to an augmented reality marker in the real world. For smartphones, the AR applications typically include global positioning system (GPS) to pinpoint the user's location and its compass to detect device orientation. The hypothesis of the study is that augmented reality applications are the most promising marketing resource for the nearest future.

\subsection{Investigation framework}

The area of international tourism was chosen for testing the hypothesis proposed in the previous section. International tourism is an integral part of the modern society. The main reasons for travelling are the following: recreation, leisure and business. It is important to briefly assess the potential of the international tourism industry. The international tourism:

- is accountable for $30 \%$ of the world's exports of services,

- constitutes $7 \%$ of overall exports of goods;

- the total contribution of travel \& tourism to global economy constitutes 7.5 trillion USD,

- represents $10 \%$ of the global GDP,

- is characterized by the fact that 1 out of 10 jobs is created in the tourism industry (employs 7 times more people than the automotive industry),

- is the basis of the service culture in many societies,

- has the predicted growth rate over the next ten years of 4\% annually (Kostin, 2016).

The well travelled generation $\mathrm{Y}$ (born in early 80 's to late 90 's) \& Z (born in early 00 's) representatives from the Russian Federation and the People's Republic of China were chosen to test the proposed hypothesis using the horizon scanning methodology described earlier. The number of travellers under investigation from each country: 500 .

\subsection{Results}

Based on the performed investigation it was discovered that the main areas for augment reality applications in international tourism are: navigation, translation, tourist attractions and information gathering. A detailed description of each area is presented in picture 2 .
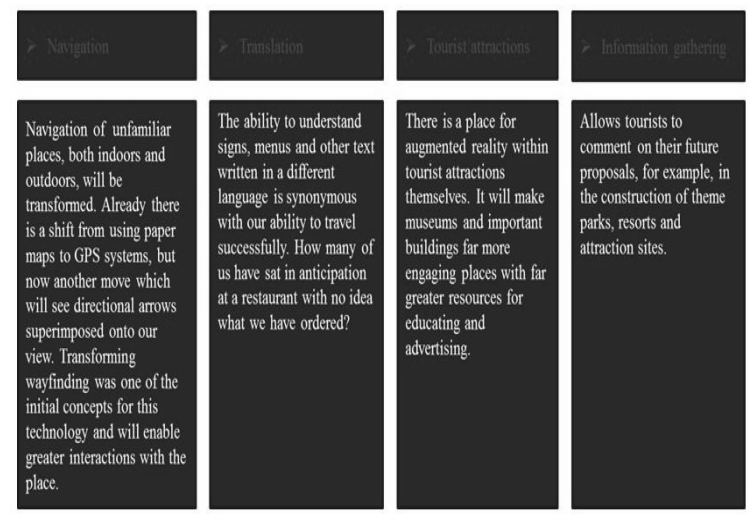

Picture 2 Augmented reality applications in international tourism

After applying the foresight methodology for the reference group is was discovered that the most promising areas for augmented reality applications are searching for tourism destinations and unknown locations, airlines and airport, hotel bookings, event management and receiving information on tourist attractions, which is schematically represented in picture 3 .

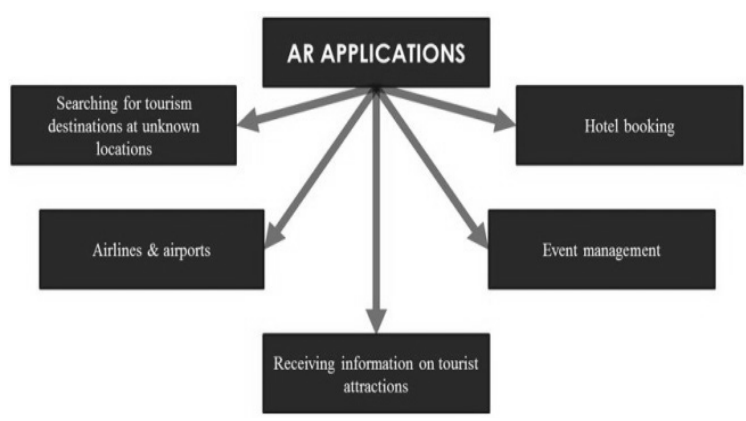

Picture 3 Most promising areas for augmented reality application

The results of the study are presented in table 1.

Table 1 Market potential for the AR applications.

\begin{tabular}{|c|c|c|}
\hline \multirow{2}{*}{ Applications area } & \multicolumn{2}{|c|}{ Potential AR customer base } \\
\hline Tourist destinations search & Russia \% & China \% \\
\hline Airlines \& airports & 100 & 100 \\
\hline Hotel booking & 87 & 87 \\
\hline Information on tourist & 84 & 100 \\
\hline attractions & 100 & 100 \\
\hline Event management & 87 & 100 \\
\hline$\Sigma$ & 91,6 & 97,4 \\
\hline
\end{tabular}


It is clear, that based on the analysis of the Russian and Chinese markets the overall potential for two markets constitutes $94,5 \%$ of the generation $\mathrm{Y}$ and $\mathrm{Z}$ customer base. These findings prove the validly of the hypothesis that augmented reality applications are the most promising marketing resource for the nearest future stated in the previous section.

As of the end of 2016, the AR mobile apps generated $\$ 2$ billion in revenue. According to Digi-Capital (2016), the market has the full frame potential to grow to $\$ 120$ billion by 2020 . Nearly half that revenue is expected to come from sales of AR hardware, while the remainder could come from retail, enterprise, and gaming uses. Based on our investigation, $84 \%$ to $100 \%$ of generation Y \& $\mathrm{Z}$ consumers, whose consumption patterns would shape future demand, find clear benefits in using AR applications in tourism industry, which in case of Russia \& China represents the consumption base of at least 250 million potential users.

\section{Conclusions}

In conclusion to foresight of the world trends attempt presented in this paper it should be noted that a lot of changes have taken place in recent years. The research findings show that the change of marketing trends tends to take place at a faster pace, and the same is true for the development of foresight methodology. It could be concluded that it is becoming more important to not only stay up to date with all the rapid changes taking place in the world of digitalization, but also to take possible future changes into account. Failure to recognize a fundamental trend or change and take respective action becomes critical for the survival of the business. Digital technologies and marketing resources were identified and categorized as the major trends businesses should be on the watch for.

In the world of digital technologies artificial intelligence can revolutionize business processes in any branch, whereby blockchain offers the possibility to make transactions much easier and securer for all the parties involved. Big data, being defined as another promising digital technology will help analyse and implement the enormous amounts of data companies gain through their marketing activities.

As far as the identified marketing resources are concerned, augmented reality applications seem to have the highest development potential due to the low adoption costs and high demand potential from the consumer side. The study was done to measure the AR application development potential for the tourism industry and the results have shown that $84 \%$ to $100 \%$ of generation Y \& $\mathrm{Z}$ consumers, whose consumption patterns would shape future demand, see clear benefits in using AR applications in this business field. Moreover, The AR market has all the potential to grow to $\$ 120$ billion by 2020 (Digi Capital, 2016) from only $\$ 2$ billion in revenue generated as of the end of 2016. Nearly half that revenue is expected to come from sales of AR hardware, while the remainder could come from retail, enterprise, and gaming uses. Augmented and virtual reality will be able to give consumers a completely new feeling of discovering products, not only in physically located shops, hence having a great future potential. Another marketing resource which might have the potential to change the future is the Internet of Things (IoT), which would be responsive to the demand from a growing consumer base through the integration of Internet and response models into diverse gadgets. Even though people think that social media is already at its peak, there is still a lot of potential as far as marketing on social networking platforms is concerned. Companies have the potential of gaining earned media content which allows them to share it with a growing number of consumers which would result in support for that content. SM

\section{References}

Batalier, C., \& Harris, J. (2016). Turning Artificial Intelligence into Business Value. Today. Retrieved March 11, 2017, from Accenture:

https://www.accenture.com/t20160401T100530_w__/u s-en/ acnmedia/Accenture/ConversionAssets/DotCom/Documents/Global/PDF/Technology_1 1/Accenture-Turning-Artificial-Intelligence-intoBusiness-Value.pdf

Burcher, N. (2012). Paid, Owned, Earned: Maximizing Marketing Returns in a Socially Connected World. London: Koganpage.

Cambridge Dictionary . (2017). Global Trend. Retrieved March 14, 2017, from http://dictionary.cambridge.org/de/worterbuch/englisch/ global-trend

Carlson, A., \& Lee, C. (2015). Followership and Social Media Marketing. Academy of Marketing Studies Journal , 19 (1), 80-101.

Courtney, L. (2015). The future of marketing: Thriving in a digital world. Journal of Accountancy, 219 (6), 1-4.

Davcik, N., \& Sharma, P. (2016). Marketing resources, performance, and competitive advantage: A review and future research directions. Journal of Business Research, 69 (12), 5547-5552.

Dictionary.com, LLC. (2017). Augmented reality. Retrieved January 20, 2017 from

http://www.dictionary.com/browse/augmented-reality 
Digi Capital (2016).Augmented/Virtual Reality revenue forecast revised to hit $\$ 120$ billion by 2020 . Retrieved March 10, 2017, from Digi Capital: http://www.digicapital.com/news/2016/01/augmentedvirtual-realityrevenue-forecast-revised-to-hit-120-billion-by2020/\#.WTA0_PnyiHs

European Commission. (2014). A Framework for Theory Development in Foresight. Engage today to shape tomorrow. 5th International Conference on FutureOriented Technology Analysis (FTA).

European Commission. (2015). Models of Horizon Scanning. How to integrate Horizon Scanning into European Research and Innovation Policies. Retrieved March 13, 2017, from Fraunhofer ISI: http://www.isi.fraunhofer.de/isiwAssets/docs/v/de/publikationen/CU_ERL_PW_Models -of-Horizon-Scanning.pdf

EY. (2014). Big data. Changing the way businesses compete and operate. Retrieved March 11, 2017, from EY: http://www.ey.com/Publication/vwLUAssets/EY__Big_data:_changing_the_way_businesses_operate/\% 24FILE/EY-Insights-on-GRC-Big-data.pdf

EY. (2015). Megatrends 2015. Making sense of a world in motion. Retrieved March 11, 2017, from EY: http://www.ey.com/Publication/vwLUAssets/eymegatrends-report-2015/\$FILE/ey-megatrends-report2015.pdf

Gee, R. (2016). Is the future of virtual reality mixed? Retrieved March 11, 2017, from Marketingweek: https://www.marketingweek.com/2016/11/21/is-thefuture-of-virtual-reality-mixed/

Gong, W. (2016). The Internet of Things (IOT): What is the potential of the internet of things (IOT) as a marketing tool? Retrieved March 11, 2017, from University of Twente:

http://essay.utwente.nl/70018/1/Gong_BA_BMS.pdf

Jackson, B. (2015). What is Virtual Reality? Definitions and Explanations. Retrieved March 12, 2017, from Marxent Labs: http://www.marxentlabs.com/what-is-virtualreality-definition-and-examples/

Kapteina, G. (2017). Digital Technologies and Trends 2017. How Organizations Manage Innovation. Retrieved March 12, 2017, from

\section{$\triangle$ Correspondence}

\section{Konstantin B. Kostin}

Fulbright Faculty Development Program Alumnus, University of North Florida

Faculty of Economics and Finance

Saint-Petersburg State University of Economics

Sadovaya str. 21, office 2094 St. Petersburg 191023, Russia

E-mail: kost_kos@mail.ru https://gernotkapteina.com/2017/01/17/digitaltechnologies-and-trends-how-organizations-becomedigital/

Khripunova, A., Vishnevskiy, K., Karasev, O., \& Meissner, D. (2014). Corporate Foresight for Corporate Functions: Impacts from Purchasing Functions. Strategic Change, 23 (3-4), 147-160.

Kostin, K. (2016). Augmented technology development foresight in international tourism. Proceedings of the Saint-Petersburg State University of Economics Journal, 102 (6), 57-63.

Ministry of Defence UK. (2014). Strategic Trends Programme. Global Strategic Trends - Out to 2045. Retrieved March 10, 2017, from https://www.gov.uk/government/uploads/system/upload s/attachment_data/file/348164/20140821_DCDC_GST_ 5_Web_Secured.pdf

National Intelligence Council. (2017). Global Trends. Paradox of Progress. Retrieved March 10, 2017, from National Intelligence:

https://www.dni.gov/files/documents/nic/GT-FullReport.pdf

Piirainen, K., \& Gonzalez, R. (2015). Theory of and within foresight. What does a theory of foresight even mean? Retrieved March 10, 2017, from http://orbit.dtu.dk/files/110824705/Theory_of_and_withi n_foresight.pdf

PwC. (2016, January). What is blockchain? Q\&A. Retrieved March 10, 2017, from

https://www.pwc.lu/en/fintech/docs/pwc-fintech-qawhat-is-blockchain.pdf

Rogers, C., Bacon, J., \& Chahal, M. (2016). Trends for 2017: Chatbots, social media \& Trump tactics. Retrieved March 10, 2017, from Marketingweek: https://www.marketingweek.com/2016/12/12/trends2017-chatbots-social-trump/ 